\title{
Young children's evaluations of the ingroup and of outgroups: A multi-national study
}

Mark Bennett

University of Dundee, Scotland

Rauf Karakozov

Azerbaizan Pedagogical Institute

Evanthia Lyons

University of Surrey, England

Ukraine

\author{
Martyn Barrett \\ University of Surrey, England \\ Giorgi Kipiani \\ Georgian Institute of Psychology \\ Valentyna Pavlenko \\ Kharkov State University,
}

Tatiana Riazanova

Russian Academy of Sciences 


\title{
Young children's evaluations of the ingroup and of outgroups: A multi-national study.
}

\begin{abstract}
In investigating intergroup attitudes, previous research in developmental psychology has frequently confounded ingroup favouritism and outgroup derogation. The present study, using unconfounded measures, examines the possibility that ingroup favouritism and outgroup derogation are distinct phenomena. Six-year-old children $(n=594)$ from five, culturally diverse nations were asked to make various evaluations of the national ingroup and of four national outgroups. The data indicate that although there is overwhelming evidence that young children favour the ingroup over other groups, outgroup derogation is limited in extent and appears to reproduce attitudes held by adult members of the particular nations investigated.
\end{abstract}




\section{Young children's evaluations of the ingroup and of outgroups: A multi-national study.}

Amongst developmental psychologists there exists a widely held view that prejudicial attitudes towards outgroups emerge early in life and that they are virtually inevitable. For example, Aboud (1988), in a significant monograph, noted that children are quick to identify similarities and differences between themselves. Moreover, she asserted that "Dissimilar people are disliked" (p.24). Similarly, Bugental and Goodnow (1998) in a chapter in the Handbook of Child Psychology, speak of "the derogation of outgroup members that becomes focal in middlechildhood" (p. 404). Such a view of ingroup-outgroup attitudes, arguably, is an outcome of decades of research that has confounded the measurement of ingroup positivity and outgroup negativity.

In an important and much-cited paper, Brewer (1979) reviewed and reconsidered the substantial social psychological literature on intergroup attitudes and behaviour, noting a pervasive confounding of ingroup favouritism and outgroup derogation. That is, on the basis of the bulk of social psychological work up until that point, it was not possible to judge whether there existed a tendency toward enhancement of the ingroup or deprecation of outgroups. Thus, Brewer made the conceptually uncontroversial point that ingroup love is not the mirror image of outgroup hatred. Two decades later, reviewing the more recent research on adults, she has concluded that, "Findings from both cross-cultural research and laboratory experiments support the ...view that ingroup identification is independent of negative attitudes towards outgroups (Brewer (1999) p.429)

Recently, Cameron, Alvarez, Ruble and Fuligni (2001) have drawn attention to the same problem in the developmental literature, a problem that goes back at least half a century. In a detailed account of the extant work, they observe that, "...much of the past research has relied on measures or statistical analyses that have confounded ingroup positivity and outgroup negativity. Thus, in these studies it is not possible to determine whether children's differential responses were the result of outgroup derogation rather than simple ingroup favouritism" (p.121). For example, in research that was to achieve classic status, Clark and Clark (1947) presented black and white dolls to children and asked them, for example, to indicate the doll with which they would prefer to play. White children showed a strong preference for the white doll, a finding that was taken to indicate racial prejudice. Many researchers subsequently adopted and adapted this methodology (e.g. Asher \& Allen, 1969; Vaughan 1964; Morland 1969) and produced very similar findings to those of Clark and Clark. Despite the widespread use of this method and its variants, it is clear that expressed preferences for the ingroup do not, ipso facto, provide a basis for inferring negative attitudes toward the outgroup.

More recent measures, such as the Preschool Racial Attitude Measure (PRAM; Williams, Best \& Boswell, 1975) have perpetuated the problem of confounding in the measurement of in- and outgroup attitudes. Thus, in the PRAM children are provided with a list of positive attributes (e.g. nice, smart and kind) and negative attributes (e.g. dirty, bad and ugly) and are asked to say whether those attributes are applicable to a black or white person. Insofar as this measure requires a forced choice between the in- and outgroup, it necessarily confounds ingroup favouritism and outgroup derogation.

More recently, in developing the Multi-response Racial Attitude measure (MRA), Doyle and Aboud (1995) sought to obviate this problem. The MRA requires 
that children allocate positive and negative attributes among boxes representing different racial groups. Importantly, children are given the opportunity to allocate each attribute to both groups considered, for example, saying that both black and white children are good. However, as Cameron et al. (2001) have pointed out, the problem of confounding persists: "Although the MRA provides children with an option to choose both groups... it still confounds the evaluation of the ingroup and the outgroup as children are not given an option to say that none of the groups have that attribute" (p.120). Thus, particularly in the case of negative attributes, children may consider that neither group possesses such attributes, but, in being requested to give a response, are likely to favour the ingroup and thus may provide a response that gives the misleading impression that they dislike the outgroup.

Within the social psychological literature, Mummendey and her colleagues (Mummendey \& Otten, 1996; Mummendey, Otten \& Berger, 2000) have noted that although measures are now typically unconfounded, there has been a tendency to focus largely upon the discriminatory allocation of positive attributes or stimuli. Thus, research has typically examined the differential allocation of money or points to ingroups and outgroups, rather than negative phenomena, such as negative trait attributions or aversive stimuli, like loud noise. Mummendey has proposed a positive-negative asymmetry in social discrimination, such that ingroup-favouring biases should be weaker in the context of negative rather than positive stimuli. Her own work (e.g. Mummendey, et al., 2000) provides substantial confirmation of this proposal and underlines the need not only to measure ingroup and outgroup attitudes separately, but to provide participants with the possibility of expressing both positive and negative views .

Only a very limited number of developmental studies have measured ingroup and outgroup attitudes independently and afforded participants the opportunity to provide both positive and negative views of the ingroup and outgroups. In a laboratory-based study, Yee and Brown (1992) showed that 3- to 9-year-old children who had been divided into two artificial groups were more favourable toward their own group than the other group, but they did not express negative attitudes toward the other group. It is important, however, to supplement such laboratory-based research with work that examines attitudes in the context of groups that have real histories that give rise to socially-shared images, or social representations (Moscovici, 1981), of one another. Such representations are clearly at the heart of relations between groups that exist within the wider society, and indeed between societies.

In one of the few studies to examine 'real' groups, Verkuyten (2001) addressed 10-year-old Dutch children's attitudes toward the national ingroup and the Americans, Germans and Turks. His research demonstrated both ingroup bias and that different processes subserve ingroup and outgroup attitudes. Similarly, Rutland (1999) presented British children, aged between 6 and 16 years, with a photograph evaluation task in which they were required to indicate their liking or disliking of specific people purportedly representing five nationalities. Evidence of ingroup favouritism was limited to children of 10 years and older. Outgroup derogation too was found only from 12 years of age and with respect only to one national group, the Germans. A possible weakness of this study, however, is that children were required to make judgements of particular individuals. Conceivably, had children been asked to make judgements of verbally labelled groups, rather than depicted individuals, concerns about fairness may have been weakened; that is, children may have been more willing to communicate both positive and negative attitudes about global social categories than about particular people representing those categories. This possibility 
is suggested by the work of Davey (1983), who asked English children between 7 and 10 years to post cards with positive and negative traits terms into one or more boxes representing white, black and Asian people in general. Children could allocate particular terms to more than one box, and importantly, they were also provided with the opportunity to indicate that the terms applied to none of the groups. White children showed clear ingroup favouritism in that many more positive terms were attributed to the ingroup than to the two outgroups. Moreover, they attributed more negative terms to outgroups than the ingroup. Importantly, however, and consistent with Mummendey's $(1996,2000)$ work on positive-negative asymmetry in social discrimination, there was a marked reluctance, especially amongst older children, to attribute negative terms to any of the groups. Using a similar method, in which British children were asked to make group-based judgements, Bennett, Lyons, Sani and Barrett (1998) found much evidence of ingroup favouritism, though not of outgroup derogation. Specifically, children's overall evaluations of the ingroup were significantly more favourable than those of outgroups; evaluations of the latter, however, were not negative. Moreover, although children were found to assign a greater number of positive adjectives to the national ingroup than to outgroups, they did not differentiate between the various groups with respect to the number of negative adjectives assigned to them.

Findings such as these are consistent with social identity theory's central claim that individuals seek positive distinctiveness for their group. Typically this is achieved by means of social comparisons that positively differentiate the ingroup from other groups, though not necessarily by derogating those groups (Tajfel \& Turner, 1986). Such findings are also consistent with Brewer's (1999) proposals concerning group formation and functioning. Brewer asserts that, "Human beings are characterised by obligatory interdependence" (p. 433). Drawing upon Allport (1954), she notes that ingroups are "psychologically primary" in that, for adaptive reasons, attachment to and preference for the ingroup are likely to antecede the development of particular conceptions of outgroups. Brewer thus emphasises the adaptive value of ingroup attachments and argues for their universality. Crucially, she makes the case that it is only under particular and relatively unusual conditions that loyalties to the ingroup become associated with negative attitudes toward outgroups. Thus, under this analysis, developmentally, it seems reasonable to suggest that early in life children will be exposed to experiences and information that construct a highly favourable conception of the ingroup. Indeed, Billig (1995) has drawn attention to the ubiquity of "banal nationalism," that is, the mundane, almost invisible practices through which nations' conceptions of their pre-eminent status are regularly affirmed. However, such affirmations need not typically carry with them the disparagement of outgroups. Nesdale (in press), rather than emphasising the nature of ingroup-related practices to which children may be exposed, adopts a cognitive-motivational position on this matter. Thus, his social identity development theory asserts that it is selfcategorisation as an ingroup member that "activates a focus upon, and accompanying preference for, the ingroup" (p.21). However, self-categorisation does not in itself lead to negative views of outgroups.

Regardless of differences at the level of detail, all these accounts make a case for the dissociation of ingroup favouritism and outgroup prejudice. Thus, the purpose of the present paper is to examine whether young children's ingroup and outgroup attitudes are relatively independent, or instead are reciprocally related, such that positive views of the ingroup are associated with negative views of outgroups. In the study that follows, we draw upon the method of Bennett et al. (1998), but 
substantially extend that work. The theoretical focus of Bennett et al.'s study constrained the sample characteristics in a significant way: specifically, the study selected an atypical sub-sample of children who had not identified with their national group, despite being de facto members of that group. Inevitably, this samplerestriction limits the extent to which inferences can be made about the general population of children. Moreover, the mean age of the children in that study was nearly 9-years-old and it remains to determine whether younger children evince the pattern of judgements that might be expected under Brewer's analysis.

The present study focuses upon 6-year-old children, that is, an age-group which has often been identified as being especially prone to prejudicial attitudes (e.g. Aboud, 1988; Bar-Tal, 1996; Bigler \& Liben, 1993; Doyle \& Aboud, 1995; Katz \& Kofkin, 1997; Clark, Hocevar \& Dembo, 1980). This apparent susceptibility has been attributed by some to cognitive limitations (e.g. Aboud, 1988) and by others to a failure to act on social norms governing the expression of hostility toward outgroups (Rutland, in press). Regardless of possible causes of the 'peaking' of prejudicial attitudes at 6 to 7 years, evidence of dissociation of ingroup favouritism and outgroup prejudice amongst this age-group would thus be particularly important.

Finally, unlike Bennett et al.'s (1998) study, which like those of Davey (1983), Rutland (1999) and Verkuyten (2001) looked only at children from a single nation, the present study examines the issue of ingroup-outgroup attitudes in the context of a large-scale, multi-national study conducted in five culturally diverse nations:

Azerbaijan, Britain, Georgia, Russia and Ukraine. Clearly, the claims we seek to address concerning ingroup preference are universalist claims and in order to assess their validity it is necessary to look both at children from the sorts of cultures in which those claims have been made, and other cultures. On the other hand, again following Brewer $(1999,2001)$ we hypothesise that attitudes toward outgroups will be variable, reflecting the particularities of intergroup relations, rather than a generalised antipathy toward outgroups. Thus, we predict that all groups will evince ingroup preference, but that specifically negative attitudes toward outgroups will be the exception, rather than normative.

\section{Method}

Participants: A total of 594 6-year-old children from five countries participated in this study: 120 Azeri children (mean age 78.76 months, $\underline{\mathrm{SD}}=3.8$ months); 108 British children (mean age 78.2 months, $\underline{\mathrm{SD}}=2.8$ months); 126 Georgian children (mean age 79.31 months, $\underline{\mathrm{SD}}=2.98$ months); 120 Russian children (mean age 76.9 months, $\underline{\mathrm{SD}}$ $=3.6$ months); and 120 Ukrainian children (mean age 77.39 months, $\underline{\mathrm{SD}}=3.29$ months). In each national group there were approximately equal numbers of boys and girls. All children resided in or near major cities and were recruited from local schools.

Procedure: Children were seen individually as part of a broader study addressing children's beliefs and feelings about their own and other national and religious groups. Interviews took place in quiet rooms set aside for the purpose of conducting the research. Interviewers were always national ingroup members.

For the particular purposes of the present study, three measures were used: number of positive trait terms applied to own and other national groups; number of negative trait terms applied to own and other national groups; and overall evaluation of own and other national groups. (The tasks on which these measures are based are described below.) These tasks were all administered after an introductory preamble which explicitly instantiated an intergroup comparative context for the child by 
naming all the individual national groups about which the child was going to be asked questions. (Other measures not reported included language spoken, collective selfesteem, parents' religion and nationality, and contact with people from other nations.)

Each child was asked to consider five target groups that earlier pilot work had established to be familiar to them. For the British children these were the British, French, Germans, Italians and Spanish (groups which Barrett \& Short (1992), too, had found to be salient for young British children); for the children of the New Independent States of the former Soviet Union these were: Americans, Azeris, Georgians, Russians and Ukrainians. (Groups which were found to be insufficiently salient to the children of most NIS countries included the Spanish and Italians.) The nationalities were considered in randomised order.

Initially, children were introduced to a card set comprising twelve cards, each with one of the following trait adjectives on it: dirty, clean, friendly, unfriendly, clever, stupid, lazy, hardworking, happy, sad, honest, dishonest. The cards were read out to the children. Presentation of the cards was randomised.

The instructions were as follows: Here are some cards with words on them that describe people. So, we can say that some people are (word on first card in pile). And some people are (word on second card). And some people are (word on third card). Right? Now, what I want you to do is to go through all these words one by one, and I want you to sort out those words which you think can be used to describe .......people. Can you do that for me? Children were permitted to select as many or as few cards as they wished. (If there was any doubt about reading ability, the cards were read out to the child by the experimenter.)

When the child had finished, he or she was asked, Now I just want to ask you one more thing about..... people. Do you like or dislike ...... people? If the child indicated either liking or disliking, a follow-up was asked: How much? Do you like/dislike them a lot or a little?

From the first part of this task two scores were derived: one point was assigned to each positive and each negative trait term chosen, and these were independently summed to provide scores indicating overall positivity and negativity toward each country.

From the second part of the task a single score was obtained, from 1 to 5, 1 indicating strongly dislike, through 3, neither like nor dislike, to 5, strongly like.

Finally, it is important to note that the instructions and questions to children were initially prepared in English. They were then translated into the local languages of the other countries independently by two separate translators. The two translations were compared, and any discrepancies resolved by discussion. The agreed instrument was then backtranslated into English by a third independent translator. The backtranslation was compared with the original English instrument in order to ascertain whether any alteration in meaning had occurred as a result of the translation process. This process was reiterated until it was ensured that no changes in meaning had occurred in the translations from English.

\section{Results}

For each national sample, three principal sets of analyses are reported. First, we consider children's overall evaluations of their own and other groups, reporting (a) the outcomes of repeated measures analyses of variance on evaluations of the five national groups, and (b), and in order to determine whether evaluations differ from the scale's mid-point (i.e. 3), one-sample t tests on children's overall evaluations of each of the groups. Second, we report analyses of variance conducted on the numbers of positive and negative adjectives applied to the various national groups. Finally, to 
determine the extent of the reciprocal relationship, if any, between positive ingroup attitudes and negative outgroup attitudes, we provide details of correlations conducted on each of the ingroup and outgroup measures (i.e. overall evaluations of each of the groups considered, and the numbers of positive and negative adjectives attributed to those groups); however, we do not report the significant correlations between pairs of outgroup measures (e.g. between overall liking of an outgroup and number of positive and negative terms attributed to it), on the grounds that they are not relevant to the study's aims. ${ }^{\text {i }}$ (Initial analysis of the data revealed that there were significant differences between children in the overall numbers of terms selected to describe groups. For this reason, as a precaution to remove error variance, we conducted partial correlations controlling for total number of terms selected.)

(N.b. degrees of freedom are do not correspond perfectly to what would be expected on the basis of the samples' sizes owing to the loss of a very few data points in cases where children were unable or unwilling to provide responses.)

\section{Azeri sample}

A one-way repeated measures analysis of variance, with target nationality as the sole factor, revealed a highly significant effect of nationality on overall evaluations: $\underline{F}(4,116)=61.58, \underline{p}<0.001$. Simple contrasts, in which the data for the ingroup were compared against those for each of the outgroups, revealed that the ingroup was evaluated significantly more positively than any of the outgroups $(\mathrm{p}<0.001)$. (Means (and standard deviations) for each sample's overall evaluations of the five target groups (derived from the like/dislike question) are given in Table 1.)

One-sample t tests conducted on evaluations for each of the groups revealed that only for the ingroup did the mean differ significantly from the scale's midpoint: $t$ $(119)=20.2, \mathrm{p}<0.001$. Evaluations of outgroups were neutral.

Turning to the adjective selection task, the number of positive adjectives attributed to the national groups was found to differ over the five groups: $\underline{F}(4,116)=$ $57.29, \mathrm{p}<0.001$. In particular, using simple contrasts in which the ingroup was compared with each subsequent group, it was found that the ingroup was assigned a significantly greater number of positive terms than any other group $(\mathrm{p}<0.001)$. The number of negative adjectives attributed also differed over the target groups: $\underline{\mathrm{F}}$ (4, $116)=9.63, \underline{p}<0.001$. Significantly fewer such terms were applied to the ingroup than to the Russians $(\mathrm{p}<0.001)$, though not to other groups. (Tables 2 and 3 provide means, for each of the national samples, for the numbers of positive and negative adjectives attributed to the target groups.)

Finally, turning to the correlational analyses, as would be expected, strong relationships were found between ingroup measures: the number of positive and negative terms attributed to the ingroup were strongly negatively correlated: $\underline{r}=-.54$, $\mathrm{p}<0001$. That is, the greater the number of positive terms applied, the smaller the number of negative terms applied. Similarly, the overall evaluation of the ingroup negatively correlated with the number of negative attitudes attributed to the ingroup: $\mathbf{r}$ $=-.23, \mathrm{p}<01$. Other than this there were only four significant correlations, three indicating that positive attitudes toward the ingroup were associated with negative attitudes toward the Russians: we found (i) a negative correlation between the overall evaluation of the ingroup and number of positive terms applied to Russians $(\underline{r}=-.22$, $\mathrm{p}<05$; i.e. liking the ingroup is associated with the attribution of fewer positive terms to Russians); (ii) a positive correlation between the number of negative terms assigned to the ingroup and the number of positive terms assigned to Russians $(\underline{r}=.21, \underline{p}<05)$; and (iii) a negative correlation between the number of positive terms attributed to the 
ingroup and to Russians $\underline{\mathrm{r}}=-.18, \underline{\mathrm{p}}<0.05)$. Finally, a negative correlation was noted between the number of positive terms assigned to the ingroup and the number of positive terms assigned to Georgians $(\underline{r}=-.19, \underline{p}<05)$.

\section{TABLE 1 ABOUT HERE}

\section{British sample}

A significant effect of national target group on children's overall evaluations of the national groups was found: $\underline{F}(4,99)=3.96$, $\underline{p}<0.005$. Simple contrasts showed that the ingroup was not evaluated more positively than the French or Spanish, but that it was viewed more positively than the Italians $(\mathrm{p}<0.005)$, and the Germans $(\mathrm{p}<0.001)$.

The results of one-sample t tests showed that although the evaluations of the Germans and Italians did not differ from the mid-point, those for the British ( $\mathrm{t}(103)=$ $5.08, \underline{\mathrm{p}}<0.001)$, French $(\mathrm{t}(105)=3.11, \underline{\mathrm{p}}<0.005)$, and Spanish $(\underline{\mathrm{t}}(104)=2.42, \underline{\mathrm{p}}<0.05)$ were significantly more positive than would be expected by chance.

A main effect of national target group on the number of positive adjectives was found: $\underline{\mathrm{F}}(4,104)=8.36, \underline{\mathrm{p}}<0.001$. The national ingroup was attributed a greater number of such adjectives than any other group $(\mathrm{p}<0.001)$. However, there was no main effect of target group on the number of negative terms attributed: $\underline{F}(4,104)=$ $1.72, \underline{\mathrm{ns}}$.

Turning to the correlational analyses, as would be expected, the overall evaluation of the ingroup was strongly related to the number of positive terms attributed to it: $\underline{r}=$ $.34, \mathrm{p}<0.001$ ). Additionally, three correlations indicated a relationship between ingroup favouring attitudes and negative attitudes toward Germans: overall evaluation of the ingroup was correlated with the number of negative terms attributed to Germans $\underline{r}=.19, \underline{p}<0.05)$; the number of positive terms attributed to the Germans was found to negatively correlate with the number of negative terms attributed to the ingroup $(\underline{\mathrm{r}}=-.28, \underline{\mathrm{p}}<0.01)$; and the number of negative terms applied to the ingroup was correlated with the extent of overall liking of the Germans $\underline{r}=.20, \underline{p}<0.05)$. Other than these, two further correlations indicated that positive attitudes toward the ingroup were related to positive attitudes toward outgroups. Thus, a negative correlation was found between the number of positive terms attributed to the French and the number of negative terms attributed to the ingroup $(\underline{r}=-.26, \underline{p}<0.01)$ : the fewer the number of negative terms attributed to the ingroup the greater the liking of the French. A final significant correlation revealed a relationship between the overall liking of the ingroup and of Italians $(\underline{\mathrm{r}}=.2, \underline{\mathrm{p}}<0.05)$ : greater liking of the ingroup was related to greater liking of Italians. No other significant correlations were found.

\section{TABLE 2 ABOUT HERE}

\section{Georgian sample}

A main effect of national target group was found: $\underline{F}(4,121)=68.98$, $\mathrm{p}<0.001$. In particular, more positive evaluations were made of the ingroup than of any of the outgroups $(\mathrm{p}<0.001)$.

One sample t tests showed that three groups were evaluated significantly more positively than would be expected by chance: the ingroup ( $\mathrm{t}(185)=17.26, \underline{\mathrm{p}}<0.001)$, the Americans ( $\underline{\mathrm{t}}(185)=8.4, \underline{\mathrm{p}}<0.001)$ and the Russians $(\underline{\mathrm{t}}(185)=4.25, \underline{\mathrm{p}}<0.001)$. The Ukrainians were evaluated no differently from chance and the Azeris were evaluated more negatively than would be expected by chance $(\mathrm{t}(125)=-3.52$, $\mathrm{p}<0.001$ ). 
Numbers of positive terms differed over the target groups: $\mathrm{F}(4,122)=57.4$, $\mathrm{p}<0.001$. Significantly more such terms were assigned to the ingroup than any other group ( $\mathrm{p}<0.001)$.

The number of negative adjectives attributed was found to differ over groups: $\underline{\mathrm{F}}(4,122)=6.87, \mathrm{p}<0.001$. Fewer negative terms were assigned to the ingroup than to the Russians $(\mathrm{p}<0.05)$ and the Azeris $(\mathrm{p}<0.001)$, though not the Ukrainians and Americans.

Predictably, significant correlations were found between the ingroup measures: an inverse correlation was found between the number of positive and negative terms attributed $(\underline{\mathrm{r}}=-.64, \mathrm{p}<0.001)$ and overall liking was related to number of positive terms $(\underline{\mathrm{r}}=.58, \underline{\mathrm{p}}<0.001)$ and negative terms $(\underline{\mathrm{r}}=-.56, \underline{\mathrm{p}}<0.001)$. Further to these analyses there was evidence that favourable views of the ingroup were related to negative views of Russians: overall liking of the ingroup was (i) negatively correlated with liking of Russians ( $\underline{r}=-.33, \underline{p}<0.001)$; (ii) positively correlated with the number of negative terms attributed to Russians $(\underline{\mathrm{r}}=.22$, $\underline{\mathrm{p}}<0.01)$; (iii) negatively correlated with the number of positive terms attributed to Russians $(\underline{r}=-.24, \underline{p}<0.01)$. In contrast, favourable attitudes toward the ingroup were related to favourable attitudes toward Americans: (i) number of positive terms applied to the ingroup was negatively related to the number of negative terms attributed to Americans $(\underline{r}=-.33, \underline{p}<0.001)$;

(ii) number of negative terms applied to the ingroup was negatively related to the number of positive terms attributed to Americans $(\underline{r}=-.26, \underline{p}<0.01)$, but (iii) was positively related to the number of negative terms assigned to Americans $(\underline{r}=.54$, $\mathrm{p}<0.001$ ); finally, (iv) overall liking of the ingroup was negatively related to the number of negative terms attributed to the Americans $(\underline{r}=-.42, \underline{p}<0.001)($; i.e. the greater the liking for the ingroup, the lesser the dislike of the outgroup).

Additionally, there was evidence that favourable attitudes toward the ingroup were related to favourable attitudes toward Ukrainians. Thus, (i) the number of positive terms assigned to the ingroup was negatively related to the number of negative terms assigned to Ukrainians( $\underline{r}=-.23, \underline{p}<0.01)$; and (ii) overall liking of the ingroup was negatively related to the number of negative terms attributed to Ukrainians $(\underline{r}=-.24, \underline{p}<0.01)$; (iii) the number of negative terms assigned to the ingroup was negatively related to the overall liking of Ukrainians $(\underline{r}=-.32, \underline{p}<0.001)$; and (iv) overall liking of the ingroup was related to overall liking of Ukrainians ( $\underline{r}=$ $.21, \mathrm{p}<0.05)$.

\section{TABLE 3 ABOUT HERE}

\section{$\underline{\text { Russian sample }}$}

Evaluations of the five target groups differed significantly: $\underline{F}(4,115)=$ $22.82, \mathrm{p}<0.001$. Specifically, the ingroup was found to be evaluated more favourably than any of the outgroups $(\mathrm{p}<0.001)$.

Only one group, the ingroup, was found to be more positively evaluated than would be expected by chance: $\underline{\mathrm{t}}(119)=10.12, \mathrm{p}<0.001$. The Ukrainians and Americans were judged no differently from chance, whereas the Azeris (t $(119)=-$ $3.28, \underline{\mathrm{p}}<0.001)$ and Georgians $(\underline{\mathrm{t}}(119)=-3.42, \underline{\mathrm{p}}<0.001)$ were both judged significantly negatively.

The number of positive terms attributed varied significantly over the target groups: $\underline{F}(4,116)=28.2, \underline{p}<0.001$. The ingroup was favoured over every other group $(\mathrm{p}<0.001)$. Similarly, for negative terms, differences were found over groups: $\underline{F}(4$, $116)=22.84, \mathrm{p}<0.001$. The ingroup was assigned fewer negative terms than any other group $(\mathrm{p}<0.001)$. 
Correlational analysis revealed significant correlations only between ingroup measures. Thus, overall liking of the ingroup was related both to the number of positive $(\underline{r}=-.26, \underline{p}<0.01)$ and negative terms attributed to it $(\underline{r}=-.33, \underline{p}<0.001)$. Moreover, the numbers of positive and negative terms attributed were inversely related: $(\underline{\mathrm{r}}=-.73, \underline{\mathrm{p}}<0.001)$.

\section{Ukrainian sample}

A main effect of target nationality was found: $\underline{F}(4,116)=54.31, \underline{p}<0.001$. All groups but the Russians were evaluated less favourably than the ingroup $(\mathrm{p}<0.001)$.

Three groups were judged significantly favourably: the ingroup (t $(119)=$ 12.36, $\mathrm{p}<0.001)$, Americans $(\underline{\mathrm{t}}(119)=3.24, \underline{\mathrm{p}}<0.005)$ and Russians $(\underline{\mathrm{t}}(119)=13.0$, $\mathrm{p}<0.001)$. Azeris were judged no differently from chance. However, evaluations of the Georgians were significantly negative $(\mathrm{t}(119)=3.72, \mathrm{p}<0.001)$.

A main effect of target group emerged for the number of positive terms attributed: $\underline{\mathrm{F}}(4,116)=37.9, \underline{\mathrm{p}}<0.001$. For all groups but one, the ingroup was highly significantly favoured over the other group ( $\mathrm{p}<0.001)$; in the case of the Russians, the ingroup was again favoured, albeit less strongly $(\mathrm{p}<0.05)$.

The number of negative terms attributed differed significantly over groups: $\underline{F}$ $(4,116)=12.8, \mathrm{p}<0.001$. Fewer such terms were applied to the ingroup than to the Azeris, Georgians and American $(\mathrm{p}<0.01)$, though not the Russians.

As for the preceding samples, significant correlations emerged between the ingroup measures. Overall liking of the ingroup was related both to the number of positive $(\underline{r}=.21, \underline{p}<0.05)$ and negative terms attributed to it $(\underline{r}=-.28, \underline{p}<0.01)$. The number of positive and negative terms attributed was inversely related: $(\underline{r}=-.64$, $\mathrm{p}<0.0001)$.

Favourable attitudes toward the ingroup were found to be significantly related to favourable attitudes toward the Americans. Specifically, overall liking of the ingroup was related to overall liking of Americans $(\underline{r}=.21, \underline{p}<0.05)$ and the number of positive terms assigned to the ingroup was negatively related to the number of negative terms assigned to Americans $(\underline{\mathrm{r}}=-.22, \underline{\mathrm{p}}<0.05)$.

Of the two remaining correlations, one indicated that favourable attitudes toward the ingroup were associated with favourable attitudes toward outgroups, the other vice-versa. Thus, the number of positive terms attributed to the ingroup was found (i) to correlate negatively with the number of negative terms assigned to the Georgians $(\underline{r}=-.34, \underline{p}<0.001)$, but (ii) also negatively with the number of positive terms assigned to Azeris $(\underline{\mathrm{r}}=-.19, \underline{\mathrm{p}}<0.05)$.

\section{Discussion}

Overall, our findings present a consistent and clear confirmation of Brewer's $(1979,1999,2001)$ and Nesdale's (in press) contention that ingroup favouritism is not inevitably related to outgroup derogation. Moreover, they support Mummendey's (2000) contention that there exists a positive-negative asymmetry in social discrimination, such that ingroup-favouring biases are typically weaker in the context of negative rather than positive stimuli. These results are particularly noteworthy in view of Mummendey, Klink and Brown's (2001) finding that amongst adults outgroup derogation is more likely where participants have been primed with an intergroup comparison orientation than other forms of prime. Insofar as the procedure of the present study had instantiated an intergroup context, we can thus assume that children had been primed in such a way as to maximise the likelihood of outgroup 
derogation. To this extent, then, the study represents a stringent examination of Brewer's claims.

Looking at the data from the overall evaluation measure, very strong effects of ingroup favouritism are apparent. For every national sample, the ingroup mean was higher than means for nearly all outgroups (the exceptions being that British and Ukrainian children's views of the ingroup were no more positive than their views of the French and Spanish (in the case of British children) and the Russians (in the case of Ukrainian children). Moreover, all ingroup means were significantly more positive than the scale's midpoint. However, in very few instances were evaluations of outgroups significantly negative: only in the case of Georgians' evaluations of the Azeris, Russians' evaluation of Azeris and Georgians, and Ukrainians' evaluations of Georgians was there evidence of outgroup derogation, that is, cases in which means were significantly lower than the scale's midpoint). Indeed, in a greater number of cases there was evidence of outgroup positivity: significantly positive views were expressed by British children about the French and Spanish, and by Georgian and Ukrainian children about the Americans and Russians. Typically, however, outgroups were judged neutrally.

Data from the adjective attribution measure were consistent with those from the evaluation measure. In all national samples but one, the number of positive adjectives attributed to the ingroup was higher than numbers attributed to outgroups (the exception being that Ukrainian children accorded a similarly high number of adjectives to Russians as to the ingroup; the ingroup nonetheless was assigned a greater number of positive terms than the remaining groups). Despite this clear favouring of the ingroup, it is vital to note that there was no evidence of an unwillingness to credit outgroups with positive traits: the overall mean number of positive terms applied to outgroups was 2 , and in only two instances did means fall below one (specifically, Azeris' attributions to Georgians $(\underline{M}=0.94)$ and to Ukrainians $(\underline{\mathrm{M}}=0.75))$.

Turning to the attribution of negative adjectives, a slightly more complex picture emerges. For the most part, fewer negative adjectives were attributed to the ingroup than to at least one of the outgroups. Only Russian children distinguished the ingroup from all other groups in this respect, whereas Ukrainian children distinguished the ingroup from three of the four outgroups (Americans, Azeris and Georgians). In the case of the Georgian children, such differentiation emerged only for two outgroups (Azeris and Russians), and in the case of Azeri children, just one outgroup (Russians). Amongst British children, however, the number of negative trait attributions did not differ over the five groups considered. Although there is some suggestion here of the sort of outgroup derogation that might be expected on the basis of earlier research (notably from the Russian and Ukrainian samples), two points need to be noted: in three of the five samples, only a minority of outgroups were assigned fewer negative traits than the ingroup. Overall, then, many groups are viewed no differently from the ingroup. Moreover, the mean numbers of negative terms attributed to outgroups were very small, the overall mean being 1.02 (as against 49 with respect to the ingroup). In fact, in 11 of the total of 20 outgroup cases, the mean number was less than one negative term attributed. As such, this evidence suggests that such outgroup derogation as exists is neither endemic nor extreme. Additionally, as Mummendey et al. (2000) have claimed, intergroup differentiation appears to be more widely sought in the context of positive than negative attributes.

The correlational analyses further support our contention that ingroup favouritism is not necessarily associated with negative views of outgroups. That is, it 
is not that strongly group-favouring attitudes are associated with pervasive dislike of outgroups. Rather, it is more typically the case that pro-ingroup attitudes are related to less favourable views of particular outgroups. For example, in the case of the British sample, several correlations revealed that children who expressed strong ingroupfavouring attitudes were more likely than those not expressing such attitudes to hold negative attitudes toward Germans, though not other groups. This is a finding that has appeared in previous studies of older British children and adolescents (Barrett \& Short, 1992; Johnson, 1973; Rutland, 1999) and indeed reflects attitudes which have endured in the popular media of the UK for decades. Similarly, Azeri children were more likely to express less positive views toward the Russians (though not other groups) if they were strongly pro-ingroup. Such a finding is understandable given that the Russians supported the Armenians, who in 1992 occupied Azeri territory; this support of the Armenians figures widely in public discourse about national affairs. Thus, to the extent that one is positively disposed to the ingroup, the actions of nations which in some way pose threats to it are likely to be correspondingly negative. Interestingly, on the other hand, there was no evidence of a relationship between inand outgroup attitudes amongst Russian children. As members of a traditionally dominant group in the context of the NIS, and formerly in the Soviet Union, this is again unsurprising insofar as Russia has shaped NIS countries' histories immensely more than it has been shaped by those countries; the significance of any of these other countries to Russia's national identity is unlikely to be as great as Russia is for the identity of other NIS countries. Thus, the general point here is that whilst we would not go so far as to claim that children of this age are knowledgeable about their country's socio-political history, it would appear that their views reflect social representations that are likely to be locally prevalent.

It is plainly not the case, then, that heightened commitment to the national ingroup results in widespread ingroup-favouring judgements. Indeed, it is noteworthy that our study also provides evidence to the effect that more favourable attitudes toward the ingroup are sometimes related to more favourable attitudes toward outgroups. Thus, group-favouring Georgian children were more favourable than those less well disposed to the ingroup in their views of Ukrainians. Similarly, numerous correlations showed that amongst both Georgians and Ukrainians ingroup-favouring attitudes were related to more favourable attitudes towards the Americans. These findings suggest the possibility, consistent with the claim made above, that such correlations reflect particular benefits deriving from certain outgroups. For example, US aid is widely advertised in the Georgian media, and insofar as one has an attachment to the nation, beneficent nations are likely to be viewed positively. Similarly, it seems conceivable that locally prevalent social representations may result in ingroup attachments becoming coupled to attitudes toward specific outgroups, such that the identity of the ingroup may in some sense be enhanced through association with the latter. For example, amongst both Georgians and Ukrainians, the correlation of positive attitudes to the ingroup and Americans might be taken to reflect perceptions of the US as characterised by modernity and affluence - significant aspirations in these relatively newly-independent states. Of course, this raises the question of why pro-American attitudes were absent in Azerbaijan and requires acknowledgement that our initial speculation stands in need of qualification. In particular, we conjecture that various identity-relevant phenomena are likely to mediate such a tendency towards outgroup- liking and suggest that, in these contexts, religious identity may be crucial: in Azerbaijan the majority of the population is Muslim whereas in the Ukraine and Georgia, as in the US, the majority is Christian. 
Such similarities in basic aspects of identity may play a pivotal role in mediating outgroup liking.

Clearly, it is not part of our aim to try to provide an account of the sociopolitical influences on national identity and attitudes. However, our findings nonetheless suggest that, other than general favouring of the ingroup, what is important to note are the particularities of children's outgroup attitudes: contrary to theoretical positions that emphasise a pervasive tendency toward ingroup bias (e.g. Aboud, 1988), our findings suggest that even young children are influenced by their nation's particular social representations of national outgroups. They are more likely to reproduce views (both negative and positive) that are widespread in their nation than to evince generalised prejudice. Thus, what is important to emphasise here is that essentially psychological accounts of prejudice, such as that of Aboud (1988), which focus on individual-level phenomena such as cognitive development, are insufficient to account for the fact that only some outgroups are negatively evaluated, and indeed that some are positively evaluated.

Taken together, then, our findings argue that although there may, as Brewer $(1999,2001)$ argues, be a universal tendency to favour the ingroup, typically this involves making relatively more favourable judgements of the ingroup than of outgroups; it does not characteristically involve the disparagement of outgroups. Furthermore, based on the foregoing discussion, we propose that our findings indicate that even the earliest commitments to the national ingroup are associated with specific, locally significant meanings about what it is to be a faithful member of the nation, such that greater levels of ingroup positivity are more likely to result in ingroup bias with respect to some outgroups rather than others. In our view it is indeed striking that children as young as 6 years, whose national identity is relatively nascent (Barrett, del Valle \& Lyons, in press), should be sensitive to the particular attitudinal commitments of adult members of their country. Such findings are consistent with Tajfel and Jahoda's (1966) early contention that "at the ages of six and seven children... agree rather more about which countries they like and dislike than about practically anything else concerning those countries..." (p.29). An essential avenue of future inquiry is the exploration of the processes of social transmission that are responsible for the reproduction of communities' views of outgroups.

Given these observations, and that it is apparently the case that there exist variations over the samples with respect to the relative distinctiveness of the ingroup, it is important that future research should explore the role of both individual- and social-level variables in mediating the extent of ingroup bias. The adult socialpsychological research literature reveals that ingroup bias varies as a function of a number of different factors, including the strength of identification with the ingroup, the presence of intergroup conflict or competition, and the perceived status of the ingroup (Brown, 1995, 2000; Hewstone, Rubin \& Willis, 2002; Oakes, Haslam \& Turner, 1994). Moreover, in laboratory-based studies, these variables have been found to be operative in children as well (e.g. Bigler, 1995; Bigler, Brown \& Markell, 2001; Nesdale \& Flesser, 2001). However, we suggest that in looking to the world beyond the laboratory, developmentally it is important to distinguish between these variables as proximal as opposed to distal causes: that is, we need to understand how far these causes operate directly, as is evidently the case for adults, and how far they are mediated by the discourse and representations of adult members of a community.

Despite providing evidence for the contention that, even amongst young children, ingroup favouritism and outgroup derogation may reflect distinct processes, it is important to enter a number of caveats to our discussion of this general 
phenomenon. Most generally, we should not be complacent about the implications of such findings for intergroup relations in everyday life. As Brewer (1999) comments, "the essence of 'subtle racism' is not the presence of strong negative attitudes toward minority groups, but the absence of positive sentiments toward these groups" (p.438). Thus, we need to be alert to the possibility that even amongst young children, discrimination (as expressed in terms of, for example, friendship choices, altruism, etc) may arise not out of negative attitudes, but out of less favourable views of outgroup than ingroup members.

A second caveat to enter is that this study has examined attitudes in a multigroup (rather than single ingroup-outgroup) context, something that Brewer (1979) urged be done more than two decades ago. However, ingroup-outgroup contrasts which vary on a single dimension (such as the case of black-white, or male-female relations, or the increasingly salient case of Islamic-Western relations), may conceivably invoke subtly different processes and contrasts (especially where perceptual cues to group membership exist) than obtain with respect to multi-group contexts. Specifically, in dichotomous contexts, contrast effects may be more potent and may bring with them more polarised forms of judgement. Moreover, as Brewer (2001) has noted, when differentiation between groups is defined in terms of a single dimension, vulnerability to threats to inclusion and differentiation may be high. Moreover, a significant cost of maintenance of ingroup identity is likely to be high levels of distrust and antagonism toward outgroups. Thus, the familiar case of the antipathy that exists between boys and girls in early- to middle-childhood (Powlishta, in press) may reflect different intergroup processes from those examined here. Clearly, then, there are grounds for supposing that different processes may operate in these two types of context.

A third point to note is that this study has looked at intergroup attitudes at the highly abstract and inclusive level of the nation. Since the overwhelming majority of a child's peers are likely to share their nationality, it is clear that this level of categorisation has significantly less utility in everyday life than sub-national forms of categorisation, such as at the level of minorities within a nation. For this reason, national identity is unlikely to be salient in the way that many other forms of social identity may be. As a result, children are likely to be more familiar with minority identities and other forms of sub-national identity than national identity. This observation underlines the significance of our finding that young children's views reflect those of adult members of their communities (in the sense that even for these highly abstract identities they appear to be sensitive to dominant social representations). However, it also raises the question of whether different intergroup processes may operate in the context of social groups that have greater utility in children's everyday lives. Although it is clear that children are alert to, for example, ethnic differences (e.g. see Brown, 1995), it remains to determine how far our findings concerning intergroup bias and discrimination may generalise to these sorts of lower-level and more familiar groups. Thus far we have limited data in this respect. However, recent data concerning the Armenian minority in Georgia indicate that while Armenian minority children evaluate their own group significantly positively, dominant-group Georgian children do not evaluate them negatively; instead their views of Armenians are neutral. While this is an encouraging finding, we would note, in line with our preceding discussion, that it is unlikely that attitudes towards minorities can be understood in terms of single, general processes. Rather, outgroup attitudes will need to be understood in terms of a variety of interacting factors, including individual and developmental processes, but crucially too the intergroup 
realities of competition, disadvantage and privilege that exist between groups, and the social representations with which they are associated.

Finally, although we have made the case that ingroup favouritism typically does not result in negative attitudes towards outgroups, we accept (a) that contextual cues may invoke short-lived forms of social judgement that result in outgroup derogation (see for example Mummendey, Klink \& Brown (2001) who found outgroup derogation amongst adults who had been primed with an intergroup comparison orientation, though not other forms of prime), and (b) that there are clearly circumstances under which a commitment to the ingroup is attended by chronic dislike of an outgroup. Understanding the latter in particular represents an especially important goal for future research. Nesdale (in press), in his social identity development theory, has argued that the emergence of chronic and extreme dislike, or prejudice, depends upon children's incorporation of negative outgroup attitudes as part of their ingroup identity. Consistent with our own earlier-stated position, Nesdale suggests that this happens when there is consensus in the child's community about the nature of particular outgroups. Additionally, he points to the role of intergroup competition and threats to the ingroup. A controversial implication of his position, and where we differ, is that following the initial categorisation of the self as a member of a particular group, there are unlikely to be age-related changes in prejudice. For Nesdale, the prevailing social context influences the salience and nature of intergroup comparisons to a much greater extent than do developmental factors. Our judgement however is that Nesdale's starting point, ingroup identity, is itself likely to undergo significant developmental change, and this change may have implications for the emergence of prejudice (see Sani and Bennett, in press; Ruble et al., in press). The exploration of such processes clearly represents an important avenue for future research.

\section{References}

Aboud, F.E. (1988) Children and Prejudice. Oxford, England: Blackwell. Allport, G.W. (1954) The Nature of Prejudice. Reading, Mass.: Addison Wesley.

Asher, S.R., \& Allen, V.L. (1969) Racial preference and social comparison processes. Journal of Social Issues, 25, 157-166.

Barrett, M., Del Valle, A., \& Lyons, E. (in press) The development of national identity and social identity processes. In Bennett, M. \& Sani, F. (Eds.) The Development of the Social Self. New York: Psychology Press.

Barrett, M., \& Short, J. (1992). Images of European people in a group of 5-10 year old English school children. British Journal of Developmental Psychology, 10, 339-363.

Bar-Tal, D. (1996) Development of social categories and stereotypes in early childhood: the case of "the Arab" concept formation, stereoptype and attitudes by Jewish children in Israel. International Journal of Intercultural Relations, 20, 341-370.

Bennett, M., Barrett, M., Lyons, E., \& Sani, F. (1998) Children's subjective identification with the group and ingroup favouritism. Developmental Psychology, 34, 902-909.

Bigler, R.S. (1995) The role of classification skill in moderating environmental influences on children's gender stereotyping: A study of the functional use of gender in the classroom. Child Development, 66, 1072-1087. 
Bigler, R.S., Brown C.S., Markell M. (2001) When groups are not created equal: Effects of group status on the formation of intergroup attitudes in children. Child Development, (4), 1151-1162.

Bigler, R.S., \& Liben, L.S. (1993) A cognitive-developmental approach to racial stereotyping and reconstructive memory in Euro-American children. $\underline{\text { Child }}$ Development, 64, 1507-1518.

Billig, M. (1995) Banal Nationalism. London: Sage.

Brewer, M.B. (1979) Ingroup bias in the minimal intergroup situation: A cognitive-motivational analysis. Psychological Bulletin, 86, 307-324.

Brewer, M.B. (1999) The psychology of prejudice: Ingroup love or outgroup hate? Journal of Social Issues, 55, 429-444.

Brewer, M.B. (2001) Ingroup identification and intergroup conflict: When does ingroup love become outgroup hate? In Ashmore, R.D., Jussim, L., \& Wilder, D. (Eds) (2001) Social identity, intergroup conflict, and conflict reduction. New York: Oxford University Press.

Brown, R. (1995) Prejudice: Its Social Psychology Oxford: Blackwell.

Brown, R. (2000). Group Processes (2nd edition). Oxford: Blackwell.

Bugental, D.B., \& Goodnow, J.J. (1998) Socialization Processes. In N.Eisenberg (Ed.) Handbook of Child Psychology. Volume 3 (Fifth edition, pp.389462). New York: Wiley.

Cameron, J.A., Alvarez, J.M., Ruble, D.N., and Fuligni, A.J. (2001) Children's lay theories about ingroups and outgroups: Reconceptualizing research on prejudice. Personality \& Social Psychology Review, 5, 118-128.

Clark, K.B., \& Clark, M.P. (1947) Racial identification and preference in Negro children. In H. Proshansky \& B. Seidenberg (eds.) Basic Studies in Social Psychology. New York: Holt Rinehart \& Winston.

Clark, A., Hocevar, D., \& Dembo, M.H. (1980) The role of cognitive development in children's explanations and preference for skin color. Developmental Psychology 16, 332-39. Britain.

Davey, A. (1983) Learning to be prejudiced: Growing up in multi-ethnic

London: Edward Arnold.

Doyle, M.B., \& Aboud, F.E. (1995) A longitudinal study of White children's racial prejudic as a social-cognitive development. Merrill Palmer Quarterly, 41, 209228.

Haslam, S. A., Turner, J. C., Oakes, P. J., McGarty, C., \& Hayes, B. K. (1992). Context-dependent variation in social stereotyping: The effects of intergroup relations as mediated by social change and frame reference. European Journal of Social Psychology, 22, 3-20.

Hewstone, M., Mark Rubin, and Hazel Willis (2002) Intergroup Bias. Annual Review of Psychology, 53, 575-604.

Hewstone, M., Rubin, M., Katz, P.A, \& Kofkin, J.A. (1997) Race, gender and young children. In S.S. Luthar, J.A. Burack, D. Cicchetti \& J.Weisz (Eds) Developmental psychopathology: Perspectives on adjustment, risk and disorder. (pp. 51-74) New York: Cambridge University Press.

Johnson, N. (1973) English children's concept of Germany. Journal of Social Psychology, 90, 269-267.

Moscovici, S. (1981) On social representations. In J.P. Forgas (ed) Social Cognition. London: Academic Press. 
Morland, J.K. (1969) Race awareness among American and Hong Kong Chinese children. American Journal of Sociology, 75, 360-374.

Mummendey, A., \& Otten S., (1996) The positive-negative asymmetry of social discrimination: A challenge to social identity theory. International Journal of Psychology, 31, 1133-1133.

Mummendey, A., Otten S., \& Berger, U. (2000) Positive-negative asymmetry in social discrimination: Valence of evaluation and salience of categorisation. Personality \& Social Psychology Bulletin, 26, 1258-1270.

Mummendey, A., Klink, A., \& Brown, R. (2001) Nationalism and patriotism: National identification and outgroup rejection. British Journal of Social Psychology, 40, 159-172.

Nesdale, D. (in press) Social identity processes and children's ethnic prejudice. In M. Bennett \& F. Sani (Eds.) The Development of the Social Self. New York: Psychology Press.

Nesdale, D., \& Flesser, D. (2001). Social identity and the development of children's group attitudes. Child Development, 72, (2), 506-517.

Oakes, P. J., Haslam, A., \& Turner, J. C. (1994). Stereotyping and Social Reality. Oxford: Blackwell.

Powlishta, K.K. (in press) Gender as a Social Category: Intergroup Processes and Gender-Role Development. In M.Bennett \& F. Sani (Eds) The Development of the Social Self. New York: Psychology Press.

Ruble, D., Alvarez, J., Bachman, M., Cameron, J., Fuligni, A., Garcia Coll, C., \& Rhee, E. (in press) The Development of a Sense of "We": The Emergence and Implications of Children's Collective Identity In M.Bennett \& F. Sani (Eds) The Development of the Social Self. New York: Psychology Press.

Rutland, A. (1999) The development of national prejudice, ingroup favouritism and self-stereotypes in British children. British Journal of Social Psychology, 38, 55-70.

Rutland, A. (in press) The development and self-regulation of intergroup attitudes in children. In M.Bennett \& F. Sani (Eds) The Development of the Social Self. New York: Psychology Press.

Tajfel, H., \& Turner, J.C. (1986) The social identity theory of intergroup behaviour. In S.Worchel \& W.G. Austin (Eds.) The Psychology of Intergroup Relations (Vol. 2). New York: Nelson Hall.

Turner, J.C. (1982) Towards a cognitive redefinition of the social group. In H.Tajfel (Ed) Social Identity and Intergroup Relations, Cambridge: Cambridge University Press.

Vaughn, G. (1964) The development of ethnic attitudes in New Zealand school children. Genetic Psychology Monographs, 70, 135-175.

Verkuyten, M. (2001) National identification and intergroup evaluations in Dutch children. British Journal of Developmental Psychology, 19, 559-571.

Williams, J.E., Best, D.L., Boswell, D.A. (1975) Children's racial attitudes in the early school years. Child Development, 46, 494-500.

Yee, M.D., \& Brown, R. (1992). Self-evaluations and intergroup attitudes in children aged three to nine. Child Development, 63, 619-629. 
Author note

Mark Bennett, Department of Psychology, University of Dundee, Scotland DD1 4HN; Martyn Barrett and Evanthia Lyons, Department of Psychology, University of Surrey, England GU2 5XH; Rauf Karakozov, Department of Psychology, Azerbaijan Pedagogical Institute, Baku, Azerbaijan; Giorgi Kipiani, Georgian Institute of Psychology, Tbilisi, Georgia; Valentyna Pavlenko, Department of Psychology, Kharkov State University, Kharkov, Ukraine; Tatiana Riazanova, Institute of Psychology, Russian Academy of Sciences, Moscow, Russia.

Sincere thanks are conveyed to all the teachers and children who participated in our research, and to the many interviewers who collected the data reported here. In addition, we are greatly indebted to our colleagues who contributed to the design of this research: Ignasi Villa, Jose Valencia, and Almudena Gimenez de la Pena. Thanks too are expressed to three anonymous reviewers for their constructive criticism of an earlier version of this paper.

The research reported in this paper was supported by a grant received from INTAS (Grant no. OPEN-97-1363) which was awarded to the Universities of Surrey, Dundee, Girona, The Basque Country, Malaga, the Russian Academy of Sciences, Kharkov State University, the Georgian Institute of Psychology and the Azerbaijan Pedagogical Institute; and by a grant from the European Communities DGXII, Human Capital and Mobility (Networks) Programme (Grant No. CHRX-CT94-0687), which was awarded to the Universities of Surrey, Dundee, Girona, Málaga, Padova and Roma "La Sapienza". The following colleagues contributed to the design of the research: Fabio Sani, Ignasi Vila, Arantza del Valle, Santi Perera, Almudena Giménez de la Peña, Luciano Arcuri, Anna Emilia Berti, Annamaria Silvana de Rosa and Anna Silvia Bombi..

Correspondence should be directed to Mark Bennett, Department of Psychology, University of Dundee, Dundee DD1 4HN, Scotland (electronic mail, M.Bennett@Dundee.ac.uk) 
Table 1

Mean overall evaluations of each of the national target groups over each of the national samples (standard deviations given in parentheses)

Target group

\begin{tabular}{|l|l|l|l|l|l|}
\hline Sample & British & French & German & Italian & Spanish \\
\hline $\begin{array}{l}\text { British }(\mathrm{n}= \\
108)\end{array}$ & $\begin{array}{l}3.57 \\
(1.14)\end{array}$ & $\begin{array}{l}3.34 \\
(1.1)\end{array}$ & $\begin{array}{l}3.00 \\
(1.24)\end{array}$ & $\begin{array}{l}3.11 \\
(1.16)\end{array}$ & $\begin{array}{l}3.28 \\
(1.22)\end{array}$ \\
\hline & & & & & \\
& American & Azeri & Georgian & Russian & Ukrainian \\
\hline $\begin{array}{l}\text { Azeri } \\
(\mathrm{n}=120)\end{array}$ & 3.11 & 4.58 & 2.87. & 3.17 & 2.96 \\
\hline $\begin{array}{l}\text { Georgian } \\
(\mathrm{n}=126)\end{array}$ & $(1.05)$ & $(0.86)$ & $(0.95)$ & $(1.33)$ & $(0.76)$ \\
\hline $\begin{array}{l}\text { Russian } \\
(\mathrm{n}=120)\end{array}$ & $(1.05)$ & 2.65 & 4.52 & 3.54 & 3.14 \\
\hline $\begin{array}{l}\text { Ukrainian } \\
(\mathrm{n}=120)\end{array}$ & $(1.65)$ & $(1.12)$ & $(0.99)$ & $(1.42)$ & $(0.83)$ \\
\hline
\end{tabular}


Table 2

Means and standard deviations of numbers of positive trait terms attributed to each target group over each of the national samples

Target group

\begin{tabular}{|l|l|l|l|l|l|}
\hline Sample & British & French & German & Italian & Spanish \\
\hline $\begin{array}{l}\text { British }(\mathrm{n}= \\
108)\end{array}$ & $\begin{array}{l}2.24 \\
(1.98)\end{array}$ & $\begin{array}{l}1.52 \\
(1.74)\end{array}$ & $\begin{array}{l}1.11 \\
(1.66)\end{array}$ & $\begin{array}{l}1.37 \\
(1.86)\end{array}$ & $\begin{array}{l}1.31 \\
(1.71)\end{array}$ \\
\hline & & & & & \\
& American & Azeri & Georgian & Russian & Ukrainian \\
\hline $\begin{array}{l}\text { Azeri } \\
(\mathrm{n}=120)\end{array}$ & 1.22 & 3.53 & .94 & 1.44 & .75 \\
\hline $\begin{array}{l}\text { Georgian } \\
(\mathrm{n}=126)\end{array}$ & $2.76)$ & $(1.78)$ & $(1.77)$ & $(1.71)$ & $(1.54)$ \\
\hline $\begin{array}{l}\text { Russian } \\
(\mathrm{n}=120)\end{array}$ & $(2.68)$ & 1.8 & 4.89 & 3.63 & 1.48 \\
\hline $\begin{array}{l}\text { Ukrainian } \\
(\mathrm{n}=120)\end{array}$ & $(2.19)$ & $2.61)$ & $(1.78)$ & $(2.3)$ & $(2.31)$ \\
\hline
\end{tabular}


Table 3

Means and standard deviations of numbers of negative trait terms attributed to each target group over each of the national samples

Target group

\begin{tabular}{|l|l|l|l|l|l|}
\hline Sample & British & French & German & Italian & Spanish \\
\hline $\begin{array}{l}\text { British }(\mathrm{n}= \\
108)\end{array}$ & 1.3 & 1.16 & 1.23 & 0.99 & 1.25 \\
& $(1.6)$ & $(1.54)$ & $(1.64)$ & $(1.45)$ & $(1.76)$ \\
\hline & American & Azeri & Georgian & Russian & Ukrainian \\
\hline Azeri & 0.4 & 0.26 & 0.4 & 1.24 & 0.3 \\
$(\mathrm{n}=120)$ & $(1.19)$ & $(0.67)$ & $(1.04)$ & $(1.74)$ & $(.94)$ \\
\hline Georgian & 0.38 & 1.18 & 0.36 & 0.95 & 0.38 \\
$(\mathrm{n}=126)$ & $(1.09)$ & $(1.85)$ & $(0.92)$ & $(1.67)$ & $(1.10)$ \\
\hline Russian & 1.57 & 1.95 & 2.02 & 0.24 & 1.82 \\
$(\mathrm{n}=120)$ & $(1.96)$ & $(2.08)$ & $(1.98)$ & $(0.75)$ & $(2.2)$ \\
\hline $\begin{array}{l}\text { Ukrainian } \\
(\mathrm{n}=120)\end{array}$ & 0.64 & 0.73 & 1.31 & 0.45 & 0.28 \\
& $(1.15)$ & $(1.23)$ & $(1.51)$ & $(0.96)$ & $(0.73)$ \\
\hline
\end{tabular}




\begin{abstract}
${ }^{\mathrm{i}}$ We have not made comparisons between countries since there exist differences between the samples that would render such analyses questionable. For example, in some samples data were collected from two sites (e.g. in Russia, Moscow \& Smolensk; in UK, London \& Dundee) whereas in others (e.g. Azerbaijain, Ukraine) they were collected from a single site (Baku \& Kharkov, respectively); in some cases the capital was included (e.g. Russia, UK), whereas in others this was not so (e.g. in Ukraine the data were collected in the city of Kharkov). Moreover, the nations are likely to differ in terms of the individualism-collectivism dimension. Such differences have implications for identity-related processes (e.g. in terms of salience of national identity, collective self-esteem, etc) that are not examined here. In consequence, the national data sets are not directly comparable.
\end{abstract}

